\title{
Clinical Application and Research Progress of Fluorine-18-sodium Fluoride PET/ CT in Benign Bone Lesions: A Review
}

Zi Wang ${ }^{1}$ and Yue Chen ${ }^{1,2^{*}}$

${ }^{1}$ Department of Nuclear Medicine, Southwest Medical University, China

${ }^{2}$ Department of Nuclear Medicine and Molecular Imaging Key Laboratory of Sichuan Province, Southwest Medical University, China

\begin{abstract}
As an excellent bone-imaging agent compared with technetium methylene diphosphonate (99mTc-MDP), fluorine18 -sodium fluoride $\left({ }^{18} \mathrm{~F}-\mathrm{NaF}\right)$ has been widely recognized for its value in bone metastasis imaging of malignant tumors. Positron Emission Tomography/Computed Tomography (PET/CT) has been established as an anatomical molecular imaging modality that combines functional and structural assessments and has been an increasingly used molecular imaging modality in human skeletal diseases. With the development of PET technology and the wide application of the routine performance of dynamic quantitative imaging, ${ }^{18} \mathrm{~F}-\mathrm{NaF}$ PET/CT has become a very promising evaluation tool for benign bone diseases. Compared with the traditional x-ray, Computed Tomography (CT), Magnetic Resonance Imaging

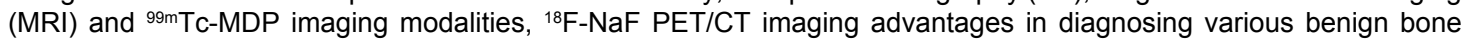
diseases, such as infection, arthritis, trauma, bone grafts, benign bone tumors, osteomatoid lesions and metabolic bone diseases, as well as monitoring clinical treatment effects, are summarized in this paper.
\end{abstract}

Keywords: ${ }^{18} \mathrm{~F}-\mathrm{NaF}$ PET/CT; Benign bone disease; Infection; Arthritis; Trauma; Bone grafts

\begin{abstract}
Abbreviations: ${ }^{99 \mathrm{~m} T c-M D P: T e c h n e t i u m ~ M e t h y l e n e ~ D i p h o s p h o n a t e ; ~}$ ${ }^{18} \mathrm{~F}-\mathrm{NaF}$ : Fluorine-18-sodium Fluoride; PET/CT: Positron Emission Tomography/Computed Tomography; CT: Computed Tomography; MRI: Magnetic Resonance Imaging; SPECT/CT: Single Photon Emission Computed Tomography/Computed Tomography.
\end{abstract}

\section{Introduction}

Benign bone diseases are very common diseases, including infection, arthritis, trauma, benign bone tumors, osteomatoid lesions and metabolic bone diseases. The current major diagnostic modalities include X-ray, Computed Tomography (CT), Magnetic Resonance Imaging (MRI), and radionuclide bone metabolism function imaging.

At present, two imaging modalities are widely used for imaging bone metabolism function. Bone scanning is performed with ${ }^{99 \mathrm{~m}} \mathrm{Tc}$ labeled methylene diphosphate ( $\left.{ }^{99 \mathrm{~m}} \mathrm{Tc}-\mathrm{MDP}\right)$ Single Photon Emission Computed Tomography/Computed Tomography (SPECT/CT) and $\left[{ }^{18} \mathrm{~F}\right]$ sodium fluoride (NaF) Positron Emission Tomography/ Computed Tomography (PET/CT) $[1] .{ }^{18} \mathrm{~F}-\mathrm{NaF}$ is a positron emitter that was first applied to bone scans by Blau et al. [2] in 1962. PET/ CT is a molecular imaging modality that combines the structural evaluation and function of the lesion for diagnosis [3]. ${ }^{18} \mathrm{~F}-\mathrm{NaF}$ PET/ $\mathrm{CT}$ is a molecular imaging modality that is increasingly used in human bone diseases [4-7]. The value of ${ }^{18} \mathrm{~F}-\mathrm{NaF}$ PET/CT in bone metastases imaging of malignant tumor has been widely recognized. Given its involvement in skeletal calcium salt metabolism [2], ${ }^{18} \mathrm{~F}-\mathrm{NaF}$ PET/CT may play an important role in assessing various benign bone diseases in the future. Although ${ }^{99 \mathrm{~m}} \mathrm{Tc}-\mathrm{MDP}$ remains the most commonly used radionuclide imaging agent for diagnosing benign bone diseases in general hospitals, ${ }^{18} \mathrm{~F}-\mathrm{NaF}$ PET/CT has attracted increasing attention given its advantages, such as high image quality, short inspection time, high spatial resolution, CT attenuation correction, and threedimensional imaging [8].

Conventional X-ray, CT, and MRI are mainly focused on structural positioning and lesion assessment, whereas ${ }^{18} \mathrm{~F}-\mathrm{NaF}$ PET/CT examination involves combined imaging of functional and anatomical positioning. The technique can be used for early disease diagnose and the identification of occult bone lesions. The method can also quantify the efficacy of medicines and evaluate the prognosis to provide assistance for early clinical treatment and therapeutic observation. This article aims to provide an overview of the imaging advantages of $18 \mathrm{~F}-\mathrm{NaF}$ PET/CT in the above benign bone disease, and summarizes the limitations of the technique, providing help for the accurate diagnosis of various benign bone diseases and guiding correct and timely treatment.

\section{The theory of ${ }^{18} \mathrm{~F}-\mathrm{NaF}$ PET/CT bone imaging}

Bone tissue is composed of organic matter and inorganic salt, and inorganic salt is mainly hydroxyapatite crystals. ${ }^{18} \mathrm{~F}-\mathrm{NaF}$ bone uptake depends on the exchange of fluoride ions with hydroxyl ions in hydroxyapatite crystals, thus forming fluorapatite [9]. The uptake of ${ }^{18} \mathrm{~F}$ in bone is dependent on blood flow, and almost all of the transmitted $18 \mathrm{~F}$ is retained by the bone after a single passage of blood $[10] .{ }^{18} \mathrm{~F}$ is mostly transported by red blood cells directly in the blood, so it has the advantages of low protein binding rate and rapid plasma clearance. Furthermore, ${ }^{18} \mathrm{~F}$ has a high affinity for bone, so it has become a superior imaging agent compared with the ${ }^{99 \mathrm{~m}} \mathrm{Tc}$-labeled phosphonate compounds [11]. After intravenous injection of ${ }^{18} \mathrm{~F}-\mathrm{NaF}$, the absorption rate of the imaging agent differs between different bone types. Compared with the level of cortical bone, the degree of $18 \mathrm{~F}-\mathrm{NaF}$ absorption in the bone marrow can be neglected [11]. The SNM practice guidelines of ${ }^{18} \mathrm{~F}-\mathrm{NaF}$ PET/CT12 indicate that the activity in adults ranges from 185 to $370 \mathrm{MBq}(5-10 \mathrm{mCi})$. Higher activity $(370 \mathrm{MBq}$ [10 mCi]) can be used in obese patients. Paediatric activities should be based on body weight $(2.22 \mathrm{MBq} / \mathrm{kg}[0.06 \mathrm{mCi} / \mathrm{kg}])$, and the range of use should be 18.5-185 MBq (0.5-5 mCi).

*Corresponding author: Yue Chen, MD, Department of Nuclear Medicine Southwest Medical University, No. 25, Taiping St, Luzhou, Sichuan 646000, People's Republic of China, Tel: +86-0830-3165722; E-mail: chenyue5523@126.com

Received June 18, 2018; Accepted June 30, 2018; Published July 05, 2018

Citation: Wang Z, Chen Y (2018) Clinical Application and Research Progress of Fluorine-18-sodium Fluoride PET/CT in Benign Bone Lesions: A Review. J Health Med Informat 9: 317. doi: 10.4172/2157-7420.1000317

Copyright: @ 2018 Wang Z, et al. This is an open-access article distributed under the terms of the Creative Commons Attribution License, which permits unrestricted use, distribution, and reproduction in any medium, provided the original author and source are credited. 
${ }^{18} \mathrm{~F}-\mathrm{NaF}$ is rapidly cleared from the plasma and excreted by the renal system due to glomerular filtration and renal tubular secretion. The clearance rate of ${ }^{18} \mathrm{~F}$ in the renal system is related to the urinary flow rate, and the clearance rate is 60 to $90 \%$ of the Glomerular Filtration Rate (GFR) during high urinary flow and 5\% of GFR during low urine flow [12]. The SNM practice guidelines [13] indicate that patients should be hydrated sufficiently to promote the rapid excretion of radiopharmaceuticals, thus reducing radiation dose and improving image quality. Patients without contraindications should be encouraged to drink more water and empty their bladders before image acquisition.

\section{Benign bone disease}

Benign bone disease indications of ${ }^{18} \mathrm{~F}-\mathrm{NaF}$ PET/CT include the following: 1) early diagnosis of infectious bone diseases, such as osteomyelitis; 2) diagnosis of arthritis; 3) diagnosis of trauma and occult fracture; 4) evaluation of bone activity; 5) diagnosis of metabolic bone disease; 6) diagnosis of osteoarthritis; and 7) early diagnosis of osteonecrosis, etc. In general, the degree of uptake of ${ }^{18} \mathrm{~F}-\mathrm{NaF}$ alone cannot be used to distinguish between benign and malignant bone diseases. Therefore, combined judgments with CT signs in PET/CT are crucial for diagnosis. Any degree of uptake of ${ }^{18} \mathrm{~F}-\mathrm{NaF}$, as long as it is significantly higher or lower than the adjacent bone tissue or the corresponding bone tissue of the contralateral side, suggests abnormal bone metabolism.

\section{Infection}

The most common infectious bone diseases examined by nuclear medicine include osteomyelitis and surgical site infection. Most osteomyelitis cases have typical clinical and imaging findings. However, the pathogenesis and development of osteomyelitis can be affected by numerous factors, including the widespread application of antibiotics and changes in bacterial virulence. Osteomyelitis cases presenting atypical clinical and radiological manifestations have gradually increased, making its imaging diagnosis and differential diagnosis more difficult. He most commonly used nuclear medicine test for the detection of osteomyelitis is three-phase imaging of bone scintigraphy, which includes blood flow, blood pool and delayed imaging. The blood flow phase is obtained immediately after the injection of the radioactive tracer ( $\left.{ }^{99 \mathrm{~m}} \mathrm{Tc}-\mathrm{MDP}\right)$ for 1 minute followed by obtaining the blood pool image, and the delayed image is performed after 2-4 hours [14]. Given the similar pharmacological behaviors of ${ }^{18} \mathrm{~F}-\mathrm{NaF}$ and $99 \mathrm{mTc}-\mathrm{MDP}$ and the rapid plasma clearance of ${ }^{18} \mathrm{~F}$, the same information revealed by perfusion and blood pool phase in $99 \mathrm{mTc}$-MDP three-phase bone scan can be obtained within 10 minutes after $18 \mathrm{~F}$ injection. Freesmeyer et al. [15] analyzed the relationship between early radioactive tracer distribution and chronic osteomyelitis in response to this characteristic of ${ }^{18} \mathrm{~F}-\mathrm{NaF}$. They collected 4 images in 1 frame/15 $\mathrm{s}$ and 4 images in 1 frame/60 s, separately, for 5 minutes for 11 patients and then plotted the ROI to obtain the SUVmax and SUVmean values. The maximal value (edSUVmax) and average value (edSUVmean) of early dynamic SUV (ed-SUV) were acquired 31 to 45 seconds after the imaging agent injection. The difference between the lesion area and the contralateral normal area was statistically significant $(\mathrm{P}<0.05)$, indicating that the quantitative analysis of the early phase of dynamic bone imaging had important value for the diagnosis of chronic osteomyelitis. Studies have demonstrated that ${ }^{18} \mathrm{~F}-\mathrm{NaF}$ PET/CT with early scanning features can replace three-phase bone scans $[15,16]$.

The surgical site infection often occurs after joint replacement surgery. Artificial joint replacement surgery as an orthopaedic surgery involves the use of engineering methods to simulate human joints, replace the damaged joints, and surgically replace the prosthesis to solve the patient's dysfunction. Currently, the arthroplasty infection rate is less than $1 \%$. However, once the infection occurs, treatment is extremely difficult. This condition was once known as a catastrophic joint replacement complication [17]. X-ray is the most commonly used examination modality for orthopedic doctors. However, Duff et al. [18] suggest that X-ray film is neither sensitive nor specific to the diagnosis of infection and its main function is to exclude aseptic loosening after joint replacement. Because PET/CT has distinctive features that combine the function and fine anatomy of lesions, some scholars have used ${ }^{18} \mathrm{~F}-\mathrm{NaF}$ PET/CT to evaluate aseptic loosening and infection after joint replacement. Hans Creutzig et al. [19] confirmed the importance of ${ }^{18} \mathrm{~F}-\mathrm{NaF}$ PET/CT in joint prosthesis infection for the first time. Olu Adesanya et al. [20] reviewed the literature and summarized that the sensitivity of ${ }^{18} \mathrm{~F}-\mathrm{NaF}-\mathrm{PET}$ for the identification of prosthesis infection was $97.04 \%$. In 2011, Kobayashi et al. [21] conducted a prospective study to identify aseptic loosening and sepsis. Images were obtained after injection of $185 \mathrm{MBq} 18 \mathrm{~F}$ fluoride for 40 minutes. By measuring the degree of uptake of ${ }^{18} \mathrm{~F}$ in the tissue surrounding the prosthesis (SUVmax), she distinguished normal, aseptically loose and infected prostheses. The mean values of normal, aseptic loosening and infected prostheses were estimated as $4.9 \pm 2.5,8.1 \pm 2.9$, and $10.5 \pm 3.4$, respectively.

\section{Arthritis}

In addition to the high uptake of bone lesions associated with skeletal structural remodelling, the most common cause of increased fluoride absorption in the bones may be arthroplasty. The term refers broadly to inflammatory diseases that occur in the human joints and their surrounding tissues caused by inflammation, infection, degeneration, trauma, or other factors, including osteoarthritis, ankylosing spondylitis and the like. Studies have demonstrated that US, MRI, and HR-pQCT imaging modalities can help clinicians diagnose arthritis early in the early stage [22]. However, Jiang Yue et al. [22] noted that these imaging modalities are still flawed, and their clinical application in improving diagnostic accuracy and guiding treatment decisions remains unclear. Radionuclide imaging is often used as a diagnostic method for this type of disease, but the diagnosis of arthritis often needs to be combined with clinical manifestations and specific laboratory tests.

Osteoarthritis $(\mathrm{OA})$ is a chronic joint disease characterized by articular cartilage degeneration and secondary hyperosteogeny. Osteoarthritis often occurs in large joints, such as knees and hips, as well as the vertebral facet joints [23]. ${ }^{18} \mathrm{~F}-\mathrm{NaF}$ PET/CT revealed that fluoride absorption in joints increased, making it a sensitive tool to detect osteoarthritis in bones. Assessment of planar bone scanning or radiographs may be limited in areas with complex anatomical structures, such as feet, whereas PET/CT has significant advantages. Yasuhide Hirata et al. [24] studied 17 patients with hip pain and used a three-dimensional pelvic femoral model to calculate the equivalent stress distribution by finite element analysis and to analyze the correlation between the calculated stress distribution and the degree of ${ }^{18} \mathrm{~F}$-fluoro-PET intake. The results revealed that the Spearman's correlation coefficient between the maximum normalized uptake value (SUVmax) and the maximum equivalent pressure were 0.752. Kobayashi et al. [6] studied 48 patients with hip arthritis. They performed radiographic evaluations based on Kellgren and Lawrence grade and minimum joint space, assessed the severity of pain, and measured the SUVmax of each joint to assess the correlation of SUVmax with imaging or clinical manifestations. The results revealed a statistically significant difference $(\mathrm{P}<0.0001)$ between the SUV values of significant pain and minor pain in the early stage of 
the X-ray examination without hip gap clearance. Fischer et al. [25] performed ${ }^{18} \mathrm{~F}-\mathrm{NaF}$ PET/CT to evaluate 28 patients with foot pain, and most of these patients underwent routine CT or MRI but did not have a definitive diagnosis. The results revealed that ${ }^{18} \mathrm{~F}-\mathrm{NaF}$ PET/ CT identified abnormalities, such as osteoarthritis, painful accessory bone, or inflammatory lesions. The treatment management of the abovementioned $46 \%$ of patients has changed, reflecting the important value of ${ }^{18} \mathrm{~F}-\mathrm{NaF} \mathrm{PET} / \mathrm{CT}$ in clinical treatment management.

Ankylosing spondylitis (AS) is a disease characterized by inflammation of sacroiliac joints and spinal attachment points and is strongly associated with HLA-b. The main symptom of this disease is inflammatory backache. Although MRI is considered the preferred imaging method to diagnose early inflammation in AS [26,27], it only exhibits high specificity in the inflammatory phase, and many patients' diagnoses were delayed for greater than seven years due to some practical application limitations [28]. Given that ${ }^{18} \mathrm{~F}-\mathrm{NaF}$ PET/CT can detect the anabolic repair process of new bone formation, it not only reveals a high uptake of the lesion during the inflammatory phase but also inflammatory repair phase. Fischer et al. [29] studied 10 patients with active AS and evaluated the difference between ${ }^{18} \mathrm{~F}-\mathrm{NaF}$ PET/CT and MRI in diagnosing sacroiliac joint and spinal cord edema using a double-blind method. The results revealed that ${ }^{18} \mathrm{~F}-\mathrm{NaF}$ PET/CT can provide patients with additional MRI evaluation information. For example, when spinal cord edema is mild, bone metabolism in adjacent vertebral bodies can be abnormal.

\section{Trauma}

At present, conventional radiography is the preferred imaging method for the detection of fractures, especially limb fractures. Because of the rapidity and wide availability of CT imaging, occult fractures that involve complex joint fractures or are not visible on standard radiographs are typically imaged with CT [30]. However, if the result of the trauma is only slight fracture of the cortex or trabecular bone, it is difficult to make a diagnosis using traditional $\mathrm{x}$-ray and CT [31]. Early diagnosis of occult fractures is very important for clinical management because delayed treatment can lead to serious complications, such as osteonecrosis, non-union, and impaired function [32]. Studies have demonstrated that MRI is a very sensitive imaging technique for describing the trabecular bone and its surrounding lesions [33], and MRI has a high diagnostic value for stress fractures and avulsion fractures, especially occult fractures [34]. Although MRI has a good ability to discriminate between cortical fractures and bone marrow edema, the examination site is limited, and occult fractures without obvious symptoms may be neglected. Numerous contraindications are noted, such as pacemakers and other metal devices. ${ }^{99 \mathrm{~m}} \mathrm{Tc}-\mathrm{MDP}$ bone imaging is a specific functional and molecular imaging with high sensitivity, and ${ }^{18} \mathrm{~F}-\mathrm{NaF}$ PET/CT can detect more lesions compared with conventional radionuclide imaging. Bone damage is common in abused children, but infants have high bone organic matter and high plasticity. Conventional $\mathrm{X}$-ray and CT may not be able to detect signs of fracture. Therefore, it may be challenging to quickly determine the full range of injury during initial assessment [35,36]. Laura et al. [37] performed ${ }^{18} \mathrm{~F}-\mathrm{NaF}$ $\mathrm{PET} / \mathrm{CT}$ and bone examination on 22 abused children under 2 years of age to assess their bone damage. PET identified a total of 200 fractures, whereas bone examination only identified 156 fractures. Among them, the sensitivity of PET for rib fractures is the highest compared with bone examination. These results indicate that ${ }^{18} \mathrm{~F}-\mathrm{NaF}$ PET/CT can be used as a global bone assessment technique for children of abuse older than 1 year of age.

\section{Bone grafts}

In various bone tumors of the limbs, allograft bone grafts are used to replace the resected bone to maintain stability and functional integrity. These grafts include cancellous bone transplantation and total bone transplantation, and bone transplantation is prone to infection, non-healing and other complications. Imaging methods, such as X-ray, CT, MRI, or bone scintigraphy, are not standardized in assessing bone grafts, making imaging assessment of bone graft controversial [38]. Winfried Brenner et al. [39] performed an ${ }^{18} \mathrm{~F}-\mathrm{NaF}$ $\mathrm{PET} / \mathrm{CT}$ quantitative assessment of the postoperative healing time of limb allograft bone grafts. They performed a total of $52{ }^{18} \mathrm{~F}-\mathrm{NaF}$ PET/ CT scans in 34 cases of cancellous bone and total bone grafts. The results revealed that the bone metabolism of cancellous bone grafts decreased by $25 \%$ between 6 and 12 months postoperatively and that SUV, KPat, and KNLR total decreased by $60-65 \%$ after two years. Total bone transplantation exhibited a $20 \%$ increase in fluoride metabolism during the first 6-12 months and decreased to $70 \%$ of the initial activity after two years. ${ }^{18} \mathrm{~F}-\mathrm{NaF}$ PET/CT is a promising tool to evaluate bone metabolism and normal healing of limb bone grafts. Gösta Ullmark et al. [40] used ${ }^{18} \mathrm{~F}-\mathrm{NaF}$ PET/CT to analyze the healing of small allograft bone grafts in 7 patients undergoing acetabular bone graft. SUV was increased by $77 \%, 91 \%$, and $20 \%$ compared with the contralateral one-week, four-months and 12-months postoperatively, respectively, confirming that ${ }^{18} \mathrm{~F}-\mathrm{NaF}$ PET/CT is a sensitive and effective imaging technology to monitor the survival condition of implanted bone.

\section{Benign tumor and osteomatoid lesions}

${ }^{18} \mathrm{~F}-\mathrm{NaF}$ PET/CT is the most sensitive imaging modality for the detection of malignant bone lesions [41] however; its evaluation of benign bone tumors is limited. Benign bone tumors and osteomatoid lesions are relatively common bone diseases. Benign tumor of bone includes osteogenic and chondrogenic tumors, whereas osteomatoid diseases include tendon sheath cyst, eosinophilic granulation swelling, and bone infarction. Traditional imaging examinations deduce benign and malignant tumors through morphological features, but no imaging studies are available that can confirm the diagnosis of benign bone tumors and osteomatoid lesions. These diseases still need to be excluded through the pathological examination of malignant diseases. Studies have demonstrated that ${ }^{18} \mathrm{~F}-\mathrm{NaF}$ bone scans exhibit increased diagnostic sensitivity and accuracy compared with $99 \mathrm{mTc}$ MDP bone scans in evaluating benign and malignant lesions in bones, although many comparisons are performed with planar single photon acquisitions [42-44]. ${ }^{18} \mathrm{~F}-\mathrm{NaF}$ PET/CT is of great value in diagnosing atypical osteoid osteoma and osteomatoid lesions, such as bone infarcts.

Osteoid osteoma is a common benign osteogenic bone tumor with unknown etiology and high incidence in young men. In $35 \%$ of cases, the precise location of osteoid osteoma may be difficult to detect because it is easily hidden by edema in the surrounding tissue. In $50 \%$ of cases, osteoid osteoma has atypical imaging findings, which may lead to misdiagnosis [45]. More difficulties are encounter when locating the tumor nest of osteoid osteoma using conventional X-ray and CT examinations. In contrast, ${ }^{18} \mathrm{~F}-\mathrm{NaF}$ PET/CT bone imaging with molecular imaging technology can clearly demonstrate high imaging agent uptake with the highest SUV value noted in the tumor nest, and this information in combination with anatomical effects can accurately locate the tumor nest [46].

Bone infarct refers to the pathological changes caused by ischemic necrosis of bone and bone marrow cells. The condition is characterized by calcification in the bone marrow cavity surrounded by clear fibers 
or hardened edges at borders and is often located at the backbone and metaphysis. Infarction can be mistaken for chondroid tumors (such as enchondroma, etc.). Cystic bone infarction involves the formation of cystic changes in the segment of the long bone or the flat stem, and its imaging findings can be similar to intraosseous lipomas or chondrosarcoma. It is often difficult to make a clear early diagnosis of the disease using X-ray and CT examinations; thus, this condition is easily missed and misdiagnosed. MRI exhibits increased sensitivity and specificity, typically exhibiting a map-like change in the edge of the lesion. Due to the lack of blood supply, the lesion imaging agent exhibits no or low radionuclide uptake, and reports of ${ }^{18} \mathrm{~F}-\mathrm{NaF}$ PET/ CT-based diagnosis of this disease are rare given that only one case has been reported [47].

\section{Metabolic bone disease}

Metabolic bone disease refers to bone disease caused by congenital or acquired factors that destroy or interfere with normal bone metabolism and biochemical state, resulting in bone biochemical metabolic disorders. Its pathogenesis includes abnormalities in bone resorption, bone growth and mineral deposition. Imaging features, such as X-ray or CT, of metabolic bone disease represent abnormal bone mineral density, which may be due to increased bone production, increased reabsorption, and abnormal mineralization. Morand Piert et al. [48] used ${ }^{18} \mathrm{~F}-\mathrm{NaF}$ PET/CT to measure the local bone blood flow in healthy pigs and performed correlation analysis with static and dynamic indicators of bone metabolism. The results showed that ${ }^{18} \mathrm{~F}$ can quantitatively evaluate bone tissue blood flow and metabolic activity in healthy pigs and concluded that ${ }^{18} \mathrm{~F}-\mathrm{NaF}$ PET/CT are beneficial for the follow-up of patients with metabolic bone disease.

Renal osteodystrophy is a condition characterized by decreased bone formation and/or impaired mineralization.

Clinicians recommend that patients with renal osteodystrophy undergo a bone metabolic activity measurement at least once a year to monitor the level of bone metabolism in kidney osteodystrophy and evaluate the efficacy [49]. Cristina and his colleagues performed ${ }^{18} \mathrm{~F}-\mathrm{NaF}$ PET in 11 patients with renal osteodystrophy to evaluate bone metabolic activity, and 11 healthy adults were used as controls. The results showed that ${ }^{18} \mathrm{~F}-\mathrm{NaF}$ PET/CT quantifies metabolic bone activity in patients with renal osteodystrophy and distinguish the specific form of the disease [49].

Paget disease of the bone is a chronic osteoma similar to degeneration that can cause bone swelling, deformity, and weakened strength, which subsequently cause bone pain, arthritis, deformities, and fractures. Its pathological features include accelerated bone turnover involving bone resorption and formation. At present, bisphosphate has been used in the treatment of Paget's disease and clinicians often evaluate the therapeutic effect by measuring blood or urine markers of bone resorption or formation, such as alkaline phosphatase. Installe J et al. [50] studied the therapeutic effect of bisphosphonates in 14 patients with Paget's disease using 18F-NaF PET/CT. The $18 \mathrm{~F}$ uptake of diseased bone was significantly increased compared normal bone, and the $18 \mathrm{~F}$ uptake of patients after 1 6 months of treatment with bisphosphonates was significantly reduced, demonstrating that ${ }^{18} \mathrm{~F}-\mathrm{NaF}$ PET/ CT can be used to non-invasively and accurately detect the therapeutic effect of bisphosphonates on Paget disease. Cook GJ et al. [51] used a dynamic ${ }^{18} \mathrm{~F}-\mathrm{NaF}$ PET/CT technique to quantify bone metabolic markers in 7 patients with Paget's disease of the spine. The dynamic ${ }^{18} \mathrm{~F}-\mathrm{NaF}$ PET/ CT technique exhibits value in the determination of regional metabolic parameters of focal bone disease. Chakraborty et al. [52] reported a case of a 65-year-old male patient with bladder transitional cell carcinoma with Paget's disease. $99 \mathrm{mTc}$-MDP bone scan revealed only strong skull uptake, whereas ${ }^{18} \mathrm{~F}-\mathrm{NaF}$ PET/CT revealed that the right superior pubic ramus and left ilium near sacroiliac joint also showed high uptake in addition to the skull, suggesting suspicious metastatic lesions.

Osteoporosis is a common systemic metabolic bone disease characterized by decreased bone mass per unit volume and altered bone microarchitecture, and this condition more commonly occurs in postmenopausal women and older men [53]. A serious consequence of osteoporosis is the occurrence of osteoporotic fractures, which are fractures that can occur during mild trauma or daily activities. ${ }^{18} \mathrm{~F}-\mathrm{NaF}$ $\mathrm{PET} / \mathrm{CT}$ is a convenient and non-invasive technique for studying bone formation in important osteoporotic fractures, such as the spine and pure cortical bone or trabecular bone. The diagnosis of traditional osteoporosis relies on bone biopsy and biochemical markers of blood or urine [54]. ${ }^{18} \mathrm{~F}-\mathrm{NaF}$ PET/CT can be used as a complementary technique for routine bone turnover measurement and a monitoring tool to evaluate the efficacy of treatment in clinical trials. Siddikque and colleagues studied 20 women who used diphosphate and 18 women who used tripeptide to treat postmenopausal osteoporosis. ${ }^{18} \mathrm{~F}-\mathrm{NaF}$ PET/CT could be used to simply diagnose diseases, analyze the curative effect and prognosis, and assist in the development of new drugs [55].

\section{Conclusion}

Radionuclide bone scans are widely used in clinic because of their high sensitivity and early detection of bone tumors from a metabolic perspective. At present, ${ }^{18} \mathrm{~F}-\mathrm{NaF} \mathrm{PET} / \mathrm{CT}$ exhibits great potential value in the diagnosis of benign bone disease and evaluation of treatment effects. ${ }^{18} \mathrm{~F}-\mathrm{NaF}$ PET/CT has a good diagnostic effect on common bone infectious diseases, such as osteomyelitis and surgical site infections, due to dynamic bone imaging early quantitative analysis technology, and it has the potential characteristics to replace the three-phase bone scan. When used in combination with information regarding clinical manifestations and specific laboratory tests, ${ }^{18} \mathrm{~F}-\mathrm{NaF}$ PET/ CT can accurately locate complex anatomic sites and provide high fluorine uptake information during the inflammatory phase and the inflammatory repair phase of arthritis. This imaging modality is of great value in diagnosing traumatic injuries, especially occult fractures, with only a slight fracture of the cortical bone or trabecular bone, providing accurate information for the assessment of the extent of injury in abused children. ${ }^{18} \mathrm{~F}-\mathrm{NaF}$ PET/CT is also a sensitive and effective imaging technology that can monitor the survival of bone grafts. Bone benign tumors and osteomatoid lesions can be differentiated from malignant bone tumors by measuring SUV values or delaying imaging. ${ }^{18} \mathrm{~F}-\mathrm{NaF} \mathrm{PET} / \mathrm{CT}$ can be used as a supplementary technique for routine bone turnover measurement and is beneficial in the follow-up of patients with metabolic bone diseases. Although ${ }^{18} \mathrm{~F}-\mathrm{NaF}$ PET/CT has been widely used in the diagnosis and monitoring of various benign bone diseases, numerous benign bone diseases still lack experimental data, and the studies described in this paper used small samples. In the future, further comparative studies of larger patient groups are needed. In addition to benign bone disease described above, ${ }^{18} \mathrm{~F}-\mathrm{NaF}$ PET/CT technology may have the potential for further research in monitoring the early efficacy of new drugs, myositis ossificans, joint disorders syndrome, and evaluating unexplained bone pain.

${ }^{18} \mathrm{~F}-\mathrm{NaF}$ has the potential to become a gold standard for the imaging of bone function. The normal bone uptake of $18 \mathrm{~F}-\mathrm{NaF}$ was more than twice that of ${ }^{99 \mathrm{~m}} \mathrm{Tc}-\mathrm{MDP}$, and the relative uptake of ${ }^{18} \mathrm{~F}-\mathrm{NaF}$ was higher when the bone turnover was increased, and ${ }^{18} \mathrm{~F}-\mathrm{NaF}$ was 
more rapidly cleared from the blood pool. Within 20 minutes of the injection, the peak of radiopharmaceutical imaging is reached and a clear contrast between bone and background is formed. Therefore, compared with conventional SPECT/CT, ${ }^{18} \mathrm{~F}-\mathrm{NaF}$ PET/CT images have a higher target/primary ratio, and can detect lesions with a slight increase in bone turnover that cannot be detected by the former. However, there are some undeniable limitations to this technology. For example, due to the degenerative changes in the bones of the elderly, there are often concentrated areas after imaging, which brings certain difficulties for differential diagnosis. The radiation exposure of $18 \mathrm{~F}-\mathrm{NaF}$ is approximately $70 \%$ higher than that of ${ }^{99 \mathrm{~m}} \mathrm{Tc}-\mathrm{MDP}$, which may be a practical obstacle to its wider clinical application. Therefore, the development of more sensitive PET systems for solving radiation exposure problems is worth further investigation. Moreover, the current high cost of ${ }^{18} \mathrm{~F}-\mathrm{NaF}$ PET/CT examination is one of the main reasons for limiting its use in benign skeletal diseases. The actual clinical application in China is limited, and it is only limited to general hospitals with PET/CT technology and 18F-NaF cyclotrons, while it is relatively widely used in Europe and the United States. Despite these limitations, this technology with great potential still has important research significance.

\section{Acknowledgments}

This work is supported by grants from the Nuclear Medicine and Molecular Imaging Key Laboratory of Sichuan Province.

\section{References}

1. Blau M, Ganatra R, Bender MA (1972) ${ }^{18} \mathrm{~F}$-fluoride for bone imaging. Semin Nucl Med 2: 31-37.

2. Blau M, Nagler W, Bender MA (1962) Fluorine-18: a new isotope for bone scanning. Official publication. J Nucl Med 3: 332-334.

3. Even-Sapir E, Metser U, Flusser G, Zuriel L, Kollender Y, et al. (2004) Assessment of malignant skeletal disease: initial experience with ${ }^{18} \mathrm{~F}$-fluoride $\mathrm{PET} / \mathrm{CT}$ and comparison between ${ }^{18} \mathrm{~F}$-fluoride PET and ${ }^{18} \mathrm{~F}$-fluoride PET/CT. J Nucl Med 45: 272-278.

4. Draper CE, Quon A, Fredericson M, Besier TF, Delp SL, et al. (2012) Comparison of MRI and ${ }^{18} \mathrm{~F}-\mathrm{NaF}$ PET/CT in patients with patellofemoral pain. Magn Reson Imaging 36: 928-932.

5. Quon A, Dodd R, lagaru A, de Abreu MR, Hennemann S, et al. (2012) Initial investigation of ${ }^{18} \mathrm{~F}-\mathrm{NaF} \mathrm{PET} / \mathrm{CT}$ for identification of vertebral sites amenable to surgical revision after spinal fusion surgery. Eur J Nucl Med Mol Imaging 39: $1737-1744$.

6. Kobayashi N, Inaba Y, Tateishi U, Yukizawa Y, Ike H, et al. (2013) New application of 18F-fluoride PET for the detection of bone remodeling in earlystage osteoarthritis of the hip. Clin Nucl Med 38: 379-383.

7. Fogelman I, Blake GM, Cook GJ (2013) The isotope bone scan: we can do better. Europ J Nuc Med Molec Imag 40: 1139-1140.

8. Grant FD, Fahey FH, Packard AB, Davis RT, Alavi A, et al. (2008) Skeleta PET with 18F-fluoride: applying new technology to an old tracer. J Nucl Med 49: 68-78.

9. Kawaguchi M, Tateishi U, Shizukuishi K, Suzuki A, Inoue T $(2010){ }^{18}$ F-fluoride uptake in bone metastasis: morphologic and metabolic analysis on integrated PET/CT. Ann Nucl Med 24: 241-247.

10. Wootton R, Dore $\mathrm{C}(1986)$ The single-passage extraction of ${ }^{18} \mathrm{~F}$ in rabbit bones Clin Phys Physiol Mea 7: 333-343

11. Czernin J, Satyamurthy N, Schiepers C (2010) Molecular mechanisms of bone ${ }^{18} \mathrm{~F}-\mathrm{NaF}$ deposition. J Nucl Med 51: 1826-1829.

12. Segall G, Delbeke D, Stabin MG, Even-Sapir E, Fair J, et al. (2010) SNM practice guideline for sodium ${ }^{18} \mathrm{~F}$-fluoride PET/CT bone scans 1.0. J Nucl Med 51: $1813-1820$

13. Li Y, Schiepers C, Lake R, Dadparvar S, Berenji GR (2012) Clinical utility of ${ }^{18} \mathrm{~F}$-fluoride $\mathrm{PET} / \mathrm{CT}$ in benign and malignant bone diseases. Bone 50: 128-139.
14. Shammas A, Vali R, Charron M (2013) Pediatric nuclear medicine in acute care. Semin Nucl Med 43: 139-156.

15. Freesmeyer M, Stecker FF, Schierz JH, Hofmann GO, Winkens T (2014) First experience with early dynamic ${ }^{18} \mathrm{~F}-\mathrm{NaF}-\mathrm{PET} / \mathrm{CT}$ in patients with chronic osteomyelitis. Ann Nucl Med 28: 314-321.

16. Wong KK, Piert M (2013) Dynamic bone imaging with ${ }^{99 m}$ Tc-labeled diphosphonate and ${ }^{18} \mathrm{~F}-\mathrm{NaF}$ : mechanisms and applications. J Nucl Med 54 590-599.

17. Kurtz SM, Lau E, Schmier J, Ong KL, Zhao K, et al. (2008) Infection burden for hip and knee arthroplasty in the United States. J Arthroplasty 23: 984-991.

18. Duff GP, Lachiewicz PF, Kelley SS (1996) Aspiration of the knee joint before revision arthroplasty. Clin Orthop Relat Res 331: 132-139.

19. Creutzig $\mathrm{H}$ (1976) Bone imaging after total replacement arthroplasty of the hip joint A follow-up with different radiopharmaceuticals. Europ J Nuc Med 1: 177-180.

20. Adesanya O, Sprowson A, Masters J, Hutchinson C (2015) Review of the role of dynamic ${ }^{18} \mathrm{~F}-\mathrm{NaF}$ PET in diagnosing and distinguishing between septic and aseptic loosening in hip prosthesis. J Orthop Surg Res 10: 5.

21. Kobayashi N, Inaba $Y$, Choe H, Ike H, Fujimaki H (2011) Use of F-18 fluoride $\mathrm{PET}$ to differentiate septic from aseptic loosening in total hip arthroplasty patients. Clin Nucl Med 36: 156-161.

22. Yue J, Wu D, Tam LS (2018) The role of imaging in early diagnosis and prevention of joint damage in inflammatory arthritis. Expert Rev Clin Immunol 14: 499-511.

23. Rohren EM, Macapinlac HA (2017) Spectrum of Benign Bone Conditions on NaF-PET. Seminars in nuclear medicine 47: 392-396.

24. Hirata Y, Inaba Y, Kobayashi N, Ike H, Yukizawa Y, et al. (2015) Correlation between mechanical stress by finite element analysis and ${ }^{18} \mathrm{~F}$-fluoride PET uptake in hip osteoarthritis patients. J Orthop Res 33: 78-83.

25. Fischer DR, Maquieira GJ, Espinosa N, Zanetti M, Hesselmann R, et al. (2010) Therapeutic impact of ${ }^{18} \mathrm{~F}$ fluoride positron-emission tomography/computed tomography on patients with unclear foot pain. Skelet Radiol 39: 987-997.

26. Puhakka KB, Jurik AG, Schiottz-Christensen B, Hansen GV, Egund N, et al. (2004) MRI abnormalities of sacroiliac joints in early spondylarthropathy: a 1-year follow-up study. Scand J Rheumatol 33: 332-338.

27. Puhakka KB, Jurik AG, Egund N, Schiottz-Christensen B, Stengaard-Pedersen $\mathrm{K}$, et al. (2003) Imaging of sacroiliitis in early seronegative spondylarthropathy. Acta Radiol 44: 218-229.

28. Feldtkeller E (1999) Age at disease onset and delayed diagnosis of spondyloarthropathies. Z Rheumatol 58: 21-30.

29. Fischer DR, Pfirrmann CW, Zubler V, Stumpe KD, Seifert B, et al. (2012) High bone turnover assessed by ${ }^{18} \mathrm{~F}$-fluoride $\mathrm{PET} / \mathrm{CT}$ in the spine and sacroiliac joints of patients with ankylosing spondylitis: comparison with inflammatory lesions detected by whole body MRI. EJNMMI Res 2: 38 .

30. Strobel K, Vali R (2012) ${ }^{18} \mathrm{~F} \mathrm{NaF} \mathrm{PET/CT} \mathrm{Versus} \mathrm{Conventional} \mathrm{Bone} \mathrm{Scanning}$ in the Assessment of Benign Bone Disease. PET Clin 7: 249-261.

31. Sadineni RT, Pasumarthy A, Bellapa NC, Velicheti S (2015) Imaging Patterns in $\mathrm{MRI}$ in Recent Bone Injuries Following Negative or Inconclusive Plain Radiographs. J Clin Diagn Res 9: 10-13.

32. Cooney WP (2003) Scaphoid fractures: current treatments and techniques. Instr Course Lect 52: 197-208.

33. Ahn JM, El-Khoury GY (2007) Occult fractures of extremities. Radiol Clin North Am 45: 561-579.

34. Ahn JM, El-Khoury GY (2007) Role of magnetic resonance imaging in musculoskeletal trauma. Top Magn Reson Imaging 18: 155-168.

35. Mandelstam SA, Cook D, Fitzgerald M, Ditchfield MR (2003) Complementary use of radiological skeletal survey and bone scintigraphy in detection of bony injuries in suspected child abuse. Arch Dis Child 88: 387-390.

36. Zimmerman S, Makoroff K, Care M, Thomas A, Shapiro R (2005) Utility of follow-up skeletal surveys in suspected child physical abuse evaluations. Child Abuse Negl 29: 1075-1083

37. Drubach LA, Johnston PR, Newton AW, Perez-Rossello JM, Grant FD, et al (2010) Skeletal trauma in child abuse: detection with 18F-NaF PET. Radiology 255: 173-181. 
Citation: Wang Z, Chen Y (2018) Clinical Application and Research Progress of Fluorine-18-sodium Fluoride PET/CT in Benign Bone Lesions: A Review. J Health Med Informat 9: 317. doi: 10.4172/2157-7420.1000317

38. Hooten JP, Engh CA, Heekin RD, Vinh TN (1996) Structural bulk allografts in acetabular reconstruction. Analysis of two grafts retrieved at post-mortem. J Bone Joint Surg Br 78: 270-275.

39. Brenner W, Vernon C, Conrad EU, Eary JF (2004) Assessment of the metabolic activity of bone grafts with (18)F-fluoride PET. Eur J Nucl Med Mol Imaging 31: 1291-1298.

40. Ullmark G, Sorensen J, Nilsson O (2009) Bone healing of severe acetabular defects after revision arthroplasty. Acta Orthopaedica 80: 179-183.

41. Even-Sapir E, Mishani E, Flusser G, Metser U (2007) ${ }^{18} \mathrm{~F}$-Fluoride positron emission tomography and positron emission tomography/computed tomography. Semin Nucl Med 37: 462-469.

42. Bhargava $\mathrm{P}$, Hanif $\mathrm{M}$, Nash $\mathrm{C}$ (2008) Whole-body F-18 sodium fluoride PET-CT in a patient with renal cell carcinoma. Clin Nucl Med 33: 894-895.

43. Hetzel M, Arslandemir C, Konig HH, Buck AK, Nüssle K, et al. (2003) F-18 $\mathrm{NaF}$ PET for detection of bone metastases in lung cancer: accuracy, costeffectiveness, and impact on patient management. J Bone Miner Res 18: 2206 2214.

44. Gamie S, El-Maghraby T (2008) The role of PET/CT in evaluation of Facet and Disc abnormalities in patients with low back pain using ${ }^{18} \mathrm{~F}$-Fluoride. Nucl Med Rev Cent East Eur 11: 17-21.

45. Davies M, Cassar-Pullicino VN, Davies AM, McCall IW, Tyrrell PN (2002) The diagnostic accuracy of MR imaging in osteoid osteoma. Skeletal Radiol 31 559-569.

46. Drubach LA, Connolly SA, Palmer EL (2011) Skeletal scintigraphy with 18F-NaF PET for the evaluation of bone pain in children. AJR Am J Roentgeno 197: 713-719.
47. Lim JT, Moncayo VM, Alazraki N (2015) Sodium 18F-Fluoride Bone Scintigraphy in Deep Ocean Diver. Clin Nucl Med 40: 582-584.

48. Piert M, Zittel TT, Becker GA, Jahn M, Stahlschmidt A, et al. (2001) Assessment of porcine bone metabolism by dynamic. J Nucl Med 42: 1091-1100.

49. Messa C, Goodman WG, Hoh CK, Choi Y, Nissenson AR, et al. (1993) Bone metabolic activity measured with positron emission tomography and ${ }^{18} \mathrm{~F}$ fluoride ion in renal osteodystrophy: correlation with bone histomorphometry. J Clin Endocrinol Metab 77: 949-955.

50. Installe J, Nzeusseu A, Bol A, Depresseux G, Devogelaer JP (2005) ${ }^{18} \mathrm{~F}$-fluoride PET for monitoring therapeutic response in Paget's disease of bone. J Nucl Med 46: 1650-1658.

51. Cook GJ, Blake GM, Marsden PK, Cronin B, Fogelman I (2002) Quantification of skeletal kinetic indices in Paget's disease using dynamic ${ }^{18} \mathrm{~F}$-fluoride positron emission tomography. J Bone Miner Res 17: 854-859.

52. Chakraborty D, Mittal BR, Kamaleshwaran KK, Kashyap R, Bhattacharya A, et al. (2011) Urinary bladder carcinoma associated with Paget's disease of skull: Imaging findings on Tc99m-MDP bone scintigraphy, F18-Fluoride PET/CT and F18-FDG PET/CT. Indian J Nucl Med 26: 42-43.

53. Liu H, Xiong Y, Wang H, Yang L, Wang C, et al. (2018) Effects of water extract from epimedium on neuropeptide signaling in an ovariectomized osteoporosis rat model. J Ethnopharmacol 221: 126-136.

54. Blake GM, Puri T, Siddique M, Frost ML, Moore AEB, et al. (2018) Site specific measurements of bone formation using ${ }^{18} \mathrm{~F}$ sodium fluoride PET/CT. Quant Imaging Med Surg 8: 47-59.

55. Siddique M, Blake GM, Frost ML, Moore AE, Puri T, et al. (2012) Estimation of regional bone metabolism from whole-body ${ }^{18} \mathrm{~F}$-fluoride $\mathrm{PET}$ static images. Eur J Nucl Med Mol Imaging 39: 337-343. 